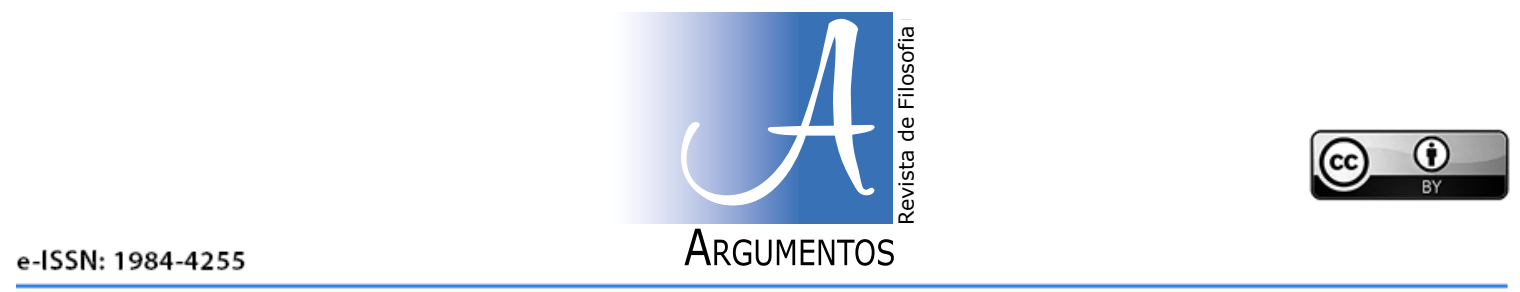

D0I: $10.36517 /$ Argumentos.26.2

\title{
Habermas e a esfera pública: as aventuras de um conceito
}

\section{Habermas and the public sphere: the adventures of a concept}

\author{
Juliano Cordeiro da Costa Oliveira \\ https://orcid.org/0000-0002-0844-6731 - E-mail: julianocordeiro81@gmail.com
}

\begin{abstract}
RESUMO
A discussão da esfera pública representou um elemento central no processo de reconstrução da Teoria Crítica na segunda metade do século XX, produzindo uma grande mudança nessa tradição teórica. Este artigo objetiva refletir a perspectiva habermasiana de esfera pública. Primeiramente, enfatizaremos como Habermas, a partir de uma obra de juventude, "Mudança Estrutural da Esfera Pública", discute o surgimento, na modernidade, dos salões, cafés e jornais, como espaços de discussão e deliberação. Entretanto, Habermas observa que interesses econômicos começaram a dominar a esfera pública, em que o poder e o dinheiro constituíam-se como forças maiores do que os discursos racionais e argumentativos, havendo, além disso, privatização do espaço público de discussão. Por conseguinte, explicitaremos como a esfera pública volta a ser discutida em seus textos mais recentes. Nestes, Habermas argumenta que a sociedade civil contemporânea se compõe de organizações e associações que captam os ecos dos problemas sociais, transmitindo-os para o sistema político, bem como colocando as questões à luz da discussão pública. Habermas destaca a existência de públicos não institucionalizados capazes de se organizar no âmbito da sociedade civil, como os movimentos sociais, tal qual um tipo de esfera pública que questiona as relações vigentes.
\end{abstract}

Palavras-chave: Habermas. Esfera Pública. Movimentos Sociais. Teoria Crítica.

\section{ABSTRACT}

The discussion of the public sphere represented a central element in the process of reconstructing Critical Theory in the second half of the 20th century, producing a major change in this 
theoretical tradition. This article aims to reflect the Habermasian perspective of the public sphere. First, we will emphasize how Habermas, from a youth work, "Structural Change of the Public Sphere", discusses the emergence, in modernity, of salons, cafes and newspapers, as spaces for discussion and deliberation. However, Habermas notes that economic interests came to dominate the public sphere, in which power and money were greater forces than rational and argumentative discourses, having, furthermore, the privatization of the public space for discussion. Therefore, we will explain how the public sphere is discussed again in its most recent texts. In these, Habermas argues that contemporary civil society is composed of organizations and associations that capture the echoes of social problems, transmitting them to the political system, as well as putting the issues in the light of public discussion. Habermas highlights the existence of non-institutionalized publics capable of organizing within the scope of civil society, such as social movements, such as a type of public sphere that questions current relations.

Keywords: Habermas. Public Sphere. Social movements. Critical Theory.

\section{A esfera pública no jovem Habermas}

Seyla Benhabib (1992, p. 73) demonstra três modelos básicos de esfera pública que se originaram respectivamente das ideias de Hannah Arendt, Kant e Habermas: o primeiro modelo é caracterizado por sua "virtude republicana" ou "virtude cívica"; o segundo, por sua vez, insere-se na tradição do liberalismo político, um modelo "legalista" de esfera pública"; já a terceira concepção, originária do pensamento de Jürgen Habermas, que pretendemos refletir neste artigo, é descrito como um modelo "discursivo" de esfera pública.

A discussão da esfera pública representou um elemento central no processo de reconstrução da Teoria Crítica na segunda metade do século XX, produzindo uma grande mudança nessa tradição teórica. Habermas passou a se preocupar cada vez mais com fundamentos normativos que permitissem estabelecer uma nova relação entre teoria crítica e teoria democrática. Pois, "a esfera pública continua sendo, sempre ainda, um princípio organizacional de nosso ordenamento político." (HABERMAS, 1984, p. 17). É em Mudança Estrutural da Esfera Pública que o jovem Habermas irá, pela primeira vez, discutir as funções e as perdas políticas da esfera pública.

A discussão acerca da esfera pública remonta aos debates filosóficos da Grécia Antiga, quando aqueles considerados cidadãos se reuniam para discutir questões relativas ao bem comum. Mesmo com a limitação do conceito de cidadania na Grécia Antiga, haja vista que muIheres, escravos e estrangeiros não podiam participar das discussões sobre o bem comum, a antiga democracia grega possuía, em realidade, um compromisso que muitas vezes faltou em outros sistemas de governo (THOMPSON, 2001).

Nos tradicionais estados monárquicos da Idade Média e início da Europa moderna, os negócios do estado eram conduzidos nos círculos fechados da corte, de modo completamente invisível à maioria da população. Quando reis, princesas e lordes apareciam diante de seus súditos, eles o faziam apenas para afirmar seu poder publicamente (visivelmente), mas não para tornar públicas (visíveis) as razões em que assentavam suas decisões políticas.

Espaços como os salões, os clubes e os cafés eram o equivalente, para Habermas, no contexto do início da Europa Moderna, às assembleias e aos mercados da Grécia Antiga. A esfera pública, desde sempre, apoiou-se na ideia do discurso, da avaliação de diferentes argumentos, opiniões e pontos de vista. De acordo com Habermas, a esfera pública burguesa exerceu, em princípio, uma função crítica contra a práxis secreta do Estado absolutista. 
Assim, uma esfera pública moderna funcionando politicamente, segundo Habermas (1984), aparece pela primeira vez na Inglaterra, no início do século XVIII. Ele explica que a esfera pública era entendida, inicialmente, como o local onde pessoas privadas se reuniam num público, buscando, por meio da práxis argumentativa, um consenso racionalmente alcançado, modificando a dominação enquanto tal. Nesse contexto, a burguesia queria passar a ter influência sobre as decisões do poder político. Objetivando isso, ela discutia com o público pensante reivindicações políticas.

Então, a esfera pública podia ser entendida como a esfera das pessoas privadas, regulamentada pela autoridade da época (nobreza), mas diretamente contra a própria autoridade, a fim de discutir com ela leis e princípios:

Os burgueses são pessoas privadas; como tais, não "governam". Por isso, as suas reivindicações de poderio contra o poder público não se dirigem contra a concentração do poder que deveria ser "compartilhado"; muito mais eles atacam o próprio princípio de dominação vigente. (HABERMAS, 1984, p. 43).

Na esfera pública burguesa, referência inicial para a análise habermasiana do espaço público, desenvolvia-se uma consciência crítica que articulava ideias contra a monarquia e o clero: indivíduos privados se engajavam numa discussão pública que, em princípio, era aberta e sem coerção. Vale lembrar que a ideia da esfera pública, em Habermas, está relacionada também com o princípio kantiano da publicidade. Para Kant, como sabemos, o esclarecimento representou a saída do homem de sua menoridade. Esta é definida como a incapacidade do homem de fazer uso de seu próprio entendimento. O uso público da razão deve ser sempre livre. "Sapere aude! Tem coragem de fazer uso de teu próprio entendimento, tal é o lema do esclarecimento" (KANT, 1985, p. 100). Aqui percebemos a interligação entre publicização de ideias com racionalidade e liberdade:

Diante do tribunal da esfera pública, todas as ações políticas devem poder ser remetidas às leis que as fundamentem e que, por sua vez, estão comprovadas perante a opinião pública como leis universais e racionais (HABERMAS, 1984, p. 132).

Os salões europeus, os cafés e os jornais eram tidos como locais propícios à discussão política, tal qual um fórum de debates. Nesses lugares, os burgueses eram socialmente reconhecidos, mas ainda desprovidos de poder:

Os herdeiros daquela sociedade de aristocratas humanistas, em contato com os intelectuais burgueses que logo passam a transformar as suas conversações sociais em aberta crítica, rebentam a ponte existente entre a forma que restava de uma sociedade decadente, a corte, e a forma primeira de uma nova: a esfera pública burguesa. (HABERMAS, 1984, p. 45).

Habermas demonstra, por exemplo, que os primeiros jornais, lançados no início do século XVII, ganharam justamente a denominação de "jornais políticos", pois traziam em suas páginas notícias sobre assembleias parlamentares, guerras, resultados de colheitas, impostos e comércio internacional, num viés crítico em relação ao poder até ali vigente: a nobreza.

Desse modo, a esfera pública intermediava, por meio da opinião pública nascida da discussão livre, ampla e da força do melhor argumento, como explica Habermas, o Estado e as necessidades da sociedade. A opinião pública era assim legitimada tal qual a única fonte verdadeira das leis. A própria esfera pública contava ainda com a separação rígida entre setor público e privado: "A linha divisória entre Estado e sociedade, fundamental para o nosso contexto, separa a esfera pública do setor privado." (HABERMAS, 1984, p. 45). 
Entretanto, Habermas observa que interesses econômicos começaram a dominar a esfera pública: poder e dinheiro constituíam-se como forças maiores do que os discursos racionais e argumentativos, havendo, além disso, privatização do espaço público de discussão. Ora, "a esfera pública burguesa se rege e cai com o princípio do acesso a todos. Uma esfera pública, da qual certos grupos fossem excluídos, não é apenas, digamos, incompleta: muito mais, ela nem sequer é uma esfera pública." (HABERMAS, 1984, p. 105). Por isso, Habermas chega a falar de uma refeudalização da esfera pública.

Este fato é decisivo para o que ele denomina de mudança estrutural da esfera pública. Segundo Habermas, há uma incompatibilidade entre os imperativos do sistema econômico capitalista, funcionando sem nenhuma regulamentação, com as exigências de um processo democrático da formação da vontade. De acordo com ele, uma esfera pública legítima deve estar enraizada também no mundo da vida, por meio da sociedade civil e de instituições democratizadas que garantam o acesso à esfera pública, bem como a participação livre, racional e argumentativa dos sujeitos nas tomadas de decisão. Porém, "à medida que o setor público se imbrica com o setor privado, este modelo (de esfera pública burguesa) se torna inútil." (HABERMAS, 1984, p. 208).

O que Habermas observa com maior gravidade é a predominância do sistema econômico em relação ao sistema sociocultural, porque há perdas consideráveis das potencialidades racionais e comunicativas no âmbito da esfera pública, em prol de interesses mercadológicos e privados: "A esfera pública burguesa desenvolve-se no campo de tensões entre Estado e sociedade. Mas de modo tal que ela mesma se torna parte do setor privado." (HABERMAS, 1984, p. 169). Por conseguinte, há ao mesmo tempo uma invasão do mundo sistêmico na esfera íntima das pessoas, uma vez que as leis do mercado penetram também na esfera reservada aos sujeitos. O raciocínio dos atores enquanto seres pertencentes a uma intersubjetividade de um espaço público, para Habermas, tenderia a se converter em consumo, e o contexto de uma comunicação pública e livre perderia seu sentido.

Contudo, J. Thompson defende a tese, com razão, de que há falhas na análise habermasiana inicial da esfera pública. Para ele, Habermas centralizou todo o seu conceito de esfera pública especificamente na burguesia, negligenciando a importância de outras formas de atividades públicas e políticas que existiram também nos séculos XVII, XVIII e XIX. Tais formas de atividades públicas e políticas não fizeram parte necessariamente da sociabilidade burguesa e em alguns casos, dela foram excluídas ou a ela se opuseram. Nessa época, existiram também movimentos sociais plebeus que se organizaram fora da chamada esfera pública burguesa, como demonstra Thompson:

[...] a relação entre a esfera pública burguesa e os movimentos populares era quase sempre conflituosa. Da mesma forma que a esfera pública burguesa emergente se definiu em oposição à autoridade tradicional do poder real, assim também se confrontou com o levante dos movimentos populares que ela procurou conter. (THOMPSON, 2001, p. 69).

De fato, a análise inicial do jovem Habermas acerca da esfera pública é limitada. Faltou a ele uma reflexão mais aprofundada sobre os movimentos sociais daquela época, bem como o papel que estes exerciam na política e na esfera pública. Outra crítica pertinente que Thompson faz a Habermas é a ênfase exagerada nos periódicos burgueses como um tipo de esfera efetivamente pública, pois, na mesma época, livros e, acima de tudo, panfletos de movimentos plebeus, circulavam antes dos jornais burgueses, promovendo também debates políticos fora da esfera do convívio burguês. 
Além disso, Thompson (2001) enfatiza que, em Mudança Estrutural da Esfera Pública, falta uma explicação suficiente de como os princípios, uma vez expressos na esfera pública burguesa, deveriam continuar a ter significado para nós ainda hoje. Thompson também argumenta que o modelo de esfera pública apresentado pelo jovem Habermas, em Mudança Estrutural da Esfera Pública, restringe-se aos costumes burgueses do século XVIII, haja vista que Habermas cita os jornais burgueses, os salões europeus e os cafés da época como exemplos de lugares propícios às deliberações políticas, ou seja, como esferas privilegiadas de discussão.

Além disso, Thompson destaca que Habermas pouco valorizou o fato das mulheres serem proibidas de frequentar os cafés europeus, sendo tais espaços predominantemente marcados pela presença masculina e burguesa. No mesmo viés de Thompson, Keith Michael Baker (1992, p.198) também ressalta que Habermas não levou em consideração justamente o problema da exclusão das mulheres na esfera pública burguesa.

Habermas assume, por sua vez, no prefácio de Mudança Estrutural da Esfera Pública, que sua investigação limitou-se, de fato, à estrutura funcional do modelo liberal da esfera pública burguesa. Entretanto, ele enfatiza que, embora existissem, é verdade, outros modelos de esferas públicas ligadas aos movimentos plebeus da época, tais esferas continuavam se orientando pelas intenções da esfera pública burguesa e pelos ideais do século XVIII.

A esfera pública burguesa personificaria princípios que iam além das formas históricas restritas onde ela atuava. Ela materializaria a ideia de que uma comunidade, reunindo-se como iguais num fórum que fosse distinto tanto da autoridade pública do Estado, como dos domínios privados da vida familiar, seria capaz de fundamentar uma opinião pública. Esta seria formada através da discussão crítica, da argumentação racional e do debate aberto a todos e livre de dominação.

Porém, a nosso ver, embora a esfera pública burguesa se baseasse no princípio do acesso universal, na prática ela estava restrita a um setor limitado da população, havendo exclusão de grande parte da sociedade, tal qual argumenta Thompson (1995). Nancy Fraser (1992), por sua vez, a partir das críticas feitas ao jovem Habermas sobre a esfera pública, defende a importância de se discutir uma nova concepção de esfera pública pós-burguesa, que considere outras formas de sociabilidades e espaços de discussão diferentes daqueles descritos pelo jovem Habermas em Mudança Estrutural da Esfera Pública.

Contudo, apesar das críticas dirigidas ao jovem Habermas, ele teve o mérito de destacar as contradições estruturais da esfera pública burguesa e a supremacia do poder e do dinheiro como meios privilegiados da ação política, assim também como a privatização de espaços potenciais de deliberação:

Esta é uma linha de crítica convincente e é para crédito de Habermas que, refletindo sobre estas questões 30 anos mais tarde, reconhece as deficiências de seu primeiro enfoque. Não somente os movimentos populares naqueles inícios foram mais importantes do que ele havia previamente admitido, mas é também claro que eles não serão adequadamente entendidos como simples "variantes" do modelo liberal da esfera pública burguesa, como ele (Habermas) de alguma forma apressadamente sugeriu. (THOMPSON, 2001, p. 69).

Entretanto, se o jovem Habermas dos tempos de Mudança Estrutural da Esfera Pública pareceu desconsiderar outras formas de deliberações diferentes da esfera burguesa tradicional, na atualidade, o herdeiro da Teoria Crítica enfatiza a importância dos movimentos sociais e da sociedade civil tal qual uma possibilidade real de articulação de debates e mudanças no rumo da política, mesmo numa sociedade profundamente desigual, em que o poder e o dinheiro continuam a ser os meios privilegiados da ação política. É o que veremos a seguir. 


\section{A esfera pública em Direito e Democracia}

Nos escritos mais recentes sobre política, como no segundo volume de Direito $e$ Democracia: entre facticidade e validade, obra originalmente lançada em 1992, Habermas (1997b) diz que a esfera pública é um "fenômeno social elementar". Ela é descrita como uma rede de comunicação de conteúdos, tomadas de posição e opiniões, em sintonia com a prática comunicativa cotidiana. Habermas argumenta que a sociedade civil contemporânea compõe-se de organizações e associações que captam os ecos dos problemas sociais ressonantes nas esferas privadas, transmitindo-os para o sistema político, bem como colocando as questões à luz da discussão pública.

Desta forma, a abordagem habermasiana atual nos permite distinguir uma dimensão de organização dos movimentos sociais, diferenciada do sistema político, mas que se relaciona ao mesmo tempo com ele. Habermas (1992), a partir de uma contextualização acerca da problemática da esfera pública na contemporaneidade, presente já em um artigo intitulado Further Reflections on the Public Sphere 1 e em grande parte no segundo volume de Direito e Democracia: entre facticidade e validade, enfatiza que a sociedade civil pode, em "certas circunstâncias", ter opiniões públicas próprias, capazes de influenciar e modificar o rumo do poder oficial.

Isto mostra uma modificação de pensamento do próprio Habermas em relação aos seus escritos de juventude de Mudança Estrutural da Esfera Pública. Pois ele, ao crer que de "uma certa forma" é possível que a sociedade civil articule mudanças no rumo da política, principalmente por meio dos movimentos sociais, afasta-se da perspectiva de teóricos como Theodor W. Adorno e Max Horheimer, que tanto o influenciaram na juventude:

Movimentos sociais podem então conduzir a atenção para determinados temas e dramatizar certos aportes. Nesse caso, a relação de dependência das massas para com o líder populista se investe: os atores na arena passam a dever sua influência à anuência de uma galeria exercitada na crítica. (HABERMAS, 1997a, p. 93).

Para os movimentos sociais, diz Habermas, é questão de vida ou morte a possibilidade de encontrar formas solidárias de organização e esferas públicas que permitam esgotar e radicalizar direitos e estruturas comunicacionais existentes. Segundo ele, os atores da sociedade civil assumem um papel surpreendentemente ativo e pleno de consequências, quando tomam consciência de situações de crise. Habermas defende que a sociedade civil, por meio das esferas públicas e das reivindicações trazidas à tona pelos movimentos sociais, é capaz de introduzir no sistema político discussões sobre os problemas existentes.

Na perspectiva de uma teoria da democracia, a esfera pública tem que reforçar a pressão exercida pelos problemas, ou seja, ela não pode limitar-se a percebê-los e a identificá-los, devendo, além disso, tematizá-los, problematizá-los e dramatizá-los de modo convincente e eficaz, a ponto de serem assumidos e elaborados pelo complexo parlamentar. E a capacidade de elaboração dos próprios problemas, que é limitada, tem que ser utilizada para um controle ulterior do tratamento dos problemas no âmbito do sistema político. (HABERMAS, 1997b, p. 91).

Então, a estrutura comunicacional da esfera pública possibilita que a sociedade civil reflita acerca dos problemas, conseguindo captá-los e identificá-los antes mesmo que o sistema político. Não é o aparelho do Estado nem as grandes organizações, argumenta Habermas, que

\footnotetext{
Nesse artigo, Habermas antecipa algumas das ideias presentes posteriormente em Direito e Democracia: Entre Facticidade e Validade, como a importância dos movimentos sociais na política atual e a constatação de esferas públicas fragmentadas na contemporaneidade.
} 
geralmente questionam os problemas existentes na sociedade civil, e sim as iniciativas vindas das esferas públicas comunicacionais. Segundo ele, mesmo que os partidos políticos passem “(...) a gravitar em torno do mercado, podem surgir movimentos contrários no interior da sociedade civil." (HABERMAS, 2003, p. 30). É nesse sentido que Habermas enfatiza que a sociedade pode influir na autotransformação do sistema político constituído. Ele destaca, portanto, a existência de públicos não institucionalizados capazes de se organizar na sociedade civil. Podemos dizer que, em Habermas, há uma compatibilização entre sistema político e esfera pública, de modo que ambos são complementares, e não excludentes um do outro.

Sob as condições das sociedades complexas, somente é possível uma democracia concebida a partir da teoria da comunicação. Para tanto, há que se inverter a relação entre centro e periferia: em meu modelo, são, sobretudo as formas de comunicação de uma sociedade civil que advêm de esferas privadas mantidas intactas, são os fluxos comunicativos de uma esfera pública vitalizada e assentada numa cultura política liberal que carregam o peso da expectativa normativa. [...] sem a força inovativa, provisoriamente efetiva, dos movimentos sociais nada muda, o mesmo valendo para as energias e imagens utópicas que impulsionam estes movimentos. (HABERMAS, 1997a, p. 87).

A esfera pública forma uma estrutura intermediária que faz a mediação entre o sistema político de um lado, e os setores privados do mundo da vida de outro. Habermas (1997b) explica que, em sociedades complexas e contemporâneas, aquilo que poderia ser uma esfera pública, como nos moldes de outrora, ramifica-se em diversos números de arenas internacionais, nacionais, regionais, comunais e subculturais, que se sobrepõem umas as outras. Estas redes se articulam objetivamente de acordo com pontos de vista funcionais, temas, círculos políticos etc. Assumem também a forma de esferas públicas "mais ou menos especializadas", porém, ainda acessíveis a um público de leigos. Por exemplo: esferas públicas literárias, eclesiásticas, artísticas, feministas, entre outras.

Além disso, aquilo que foi um dia a chamada esfera pública burguesa, descrita pelo jovem Habermas em Mudança Estrutural da Esfera Pública, ramifica-se na atualidade em três outras modalidades, levando-se em consideração a densidade da comunicação, a complexidade organizacional e o alcance comunicacional. São elas: esfera pública episódica (bares, cafés, encontros na rua), esfera pública da presença organizada (encontros de pais, público que frequenta teatro, concertos de rock, reuniões de partidos ou congresso de igrejas) e esfera pública abstrata, produzida pela mídia (leitores, ouvintes e espectadores singulares, espaIhados globalmente).

Consequentemente, apesar das diferenciações, as esferas, constituídas através da linguagem comum ordinária, são flexíveis, permitindo uma ligação entre elas próprias. Diante disso, Habermas justifica que "(...) limites sociais internos decompõem o texto da esfera pública, que se estende radicalmente em todas as direções, sendo transcrita de modo contínuo, em inúmeros pequenos textos." (HABERMAS, 1997b, p. 107). Isto é, há uma fragmentação do que um dia se chamou de esfera pública burguesa, bem como a modificação de seu conceito, inadequado para os dias atuais, haja vista o aumento da complexidade e da ramificação da sociedade civil.

Há também uma ampliação da esfera pública no âmbito mundial, porque os cidadãos deliberam acerca de questões que atingem os homens como um todo (problemas econômicos, políticos, ecológicos etc). Anthony Giddens, por exemplo, enfatiza que, na contemporaneidade, há vários movimentos sociais com suas respectivas reivindicações, naquilo que denomina de "caráter multidimensional da modernidade." (GIDDENS, 1991, p. 158). O próprio Habermas ainda, em Mudança Estrutural da Esfera Pública, deixa em aberto a questão da esfera pública, ao 
finalizar a obra destacando que o conceito de esfera pública é passível de alteração: "sendo ela (a esfera pública) mesma uma categoria histórica, também é vulnerável a uma alteração substancial." (HABERMAS, 1984, p. 290).

Há, portanto, em Habermas (1997b), esferas públicas subculturais que se sobrepõem umas às outras, cujas fronteiras reais, sociais e temporais são fluidas. Todavia, para ele, esta esfera pública contemporânea e plural, devido à sua estrutura anárquica, está muito mais exposta aos efeitos de repressão e de exclusão do poder social - distribuído desigualmente - da violência estrutural e da comunicação sistematicamente distorcida, do que a tradicional esfera pública organizada diretamente pelo complexo parlamentar, como aquela descrita pelo jovem Habermas em Mudança Estrutural da Esfera Pública.

Entretanto, a esfera pública contemporânea e plural, de maneira contraditória, tem também a vantagem de ser um meio de comunicação isento de limitações, no qual é possível captar melhor novos problemas. Assim, as esferas públicas se reproduzem, constituindo uma estrutura comunicacional, a qual tem a ver com o espaço social gerado na práxis comunicativa, por meio das argumentações e das problematizações críticas.

A democracia, em Habermas, deve ser entendida a partir da relação entre o polo do parlamento e o da participação social (a esfera pública e movimentos sociais): as decisões tomadas no âmbito do sistema político precisam ser fundamentadas e justificadas na sociedade, através de uma esfera pública vitalizada. O sistema político deve, por isso, estar ligado às redes periféricas da esfera pública, por meio de um fluxo de comunicação que parta das redes informais da esfera pública, institucionalizando-se no parlamento.

As reivindicações deliberativas acontecidas dentro e fora do complexo parlamentar formam arenas nas quais é possível acontecer uma formação racional e discursiva da opinião e da vontade, acerca de matérias relevantes para toda a sociedade. As estruturas comunicacionais das esferas públicas formam uma rede ampla de sensores que reagem à pressão de situações problemáticas, sensibilizando o poder administrativo para a resolução de problemas.

Uma esfera pública vitalizada e pulsante é o oxigênio de uma democracia. A sociedade, quando em crise, serve-se da opinião pública para atualizar os conteúdos normativos do Estado democrático de direito, protestando contra a inércia sistêmica da política institucional. A democracia é, por isso, um projeto inacabado. O Estado democrático de direito não se apresenta como uma configuração pronta, e sim como um empreendimento arriscado, delicado, falível e carente sempre de revisão, em que a esfera pública e a sociedade civil, através das deliberações e dos movimentos sociais, possuem um papel determinante, na crítica e na legitimidade do poder existente.

\section{Referências}

BAKER, K. M. Defining the public sphere in eighteenth-century France: variations on a theme by Habermas. In: CALHOUN, C. (Ed.). Habermas and the Public Sphere. Massachusetts: Massachusetts Institute of Technology, 1992.

BENHABIB, S. Models of Public Space: Hannah Arendt, the Liberal Tradition, and Jürgen Habermas. In: CALHOUN, C. (Ed.). Habermas and the Public Sphere. Massachusetts: Massachusetts Institute of Technology, 1992.

FRASER, N. Rethinking the Public Sphere: a contribution to the critique of actually existing democracy. In: CALHOUN, C. (Ed.). Habermas and the Public Sphere. Massachusetts: Massachusetts Institute of Technology, 1992. 
GIDDENS, A. As Consequências da Modernidade. São Paulo: Editora Unesp, 1991.

HABERMAS, J. Mudança Estrutural da Esfera Pública: investigações quanto a uma categoria da sociedade burguesa. Rio de Janeiro: Tempo Brasileiro, 1984.

HABERMAS, J. Further Reflections on the Public Sphere. In: CALHOUN, C. (Ed.). Habermas and the Public Sphere. Massachusetts: Massachusetts Institute of Technology, 1992.

HABERMAS, J. Uma Conversa Sobre Questões da Teoria Política: entrevista de Jürgen Habermas a Mikael Carlehedem e René Gabriels. São Paulo: Novos Estudos Cebrap, 1997a.

HABERMAS, J. Direito e Democracia: Entre Facticidade e Validade (volume II). Rio de Janeiro: Tempo Brasileiro, 1997b.

HABERMAS, J. Era das Transições. Rio de Janeiro: Tempo Brasileiro, 2003.

KANT, I. Resposta à pergunta: que é esclarecimento? In: KANT, I. Immanuel Kant: textos seletos. $2^{\text {a }}$ ed. Petrópolis: Vozes, 1985. p. 100-117.

THOMPSON, J. Ideologia e cultura moderna: teoria social crítica na era dos meios de comunicação de massa. Petrópolis: Vozes, 1995.

THOMPSON, J. A Mídia e a Modernidade: uma teoria social da mídia. 3a ed. Petrópolis: Vozes, 2001.

\section{Sobre o autor}

Juliano Cordeiro da Costa Oliveira

Doutor em Filosofia pela Universidade Federal do Ceará (UFC). Pós-doutorado em Filosofia pela Universidade Federal do Piauí (UFPI).

Recebido em: 17/10/2020.

Aprovado em: 25/01/2021.
Received: 17/10/2020.

Approved: 25/01/2021. 